\title{
POLONESES EM TERRA DE ITALIANOS: UM ESTUDO SOBRE DIVERSIDADE E CONTATO ÉTNICO NO MUNICÍPIO DE COLOMBO, PARANÁ.
}

\section{Polish in the Land of Italians: A Study on Diversity and Ethnic Contact in the Municipality of Colombo, Paraná.}

Fábio Luiz MACHIOSKI

CEVEP - Centro de Estudos Vênetos no Paraná

fabiomachioski@gmail.com https://orcid.org/0000-0002-4976-6280

RESUMO: Este estudo pretende identificar a presença dos imigrantes poloneses e seus descendentes em Colombo, Paraná. Historicamente, esta cidade da Região Metropolitana de Curitiba é conhecida pela imigração italiana, no entanto, no final do século XIX um expressivo contingente polonês também se instalou em suas terras. Sendo assim, o primeiro objetivo desta pesquisa é evidenciar a presença histórica deste grupo étnico eslavo e, ao mesmo tempo, identificar os espaços, físicos e temporais, ocupados por ele na referida municipalidade. Almeja-se também analisar os contatos que se deram entre poloneses e italianos, sob a visão dos descendentes destes últimos em relação aos primeiros. Para isto, fez-se uso da análise de narrativas como metodologia da História Oral. Nessa direção, um roteiro de entrevista foi organizado considerando a memória no âmbito da pesquisa histórica. Portanto, as fontes utilizadas são relatos orais, todos coletados, no ano de 2019, por membros do Centro de Estudos Vênetos no Paraná. Por sua vez, a análise teórica se apoia nas discussões sobre etnicidade, apresentadas por Poutignat e Streiff-Fenart, e sobre identidade pela diferenciação, apontadas por Silva. Dentro do material apurado, destacam-se discursos que podemos classificar como promotores de fronteiras etnoculturais construídas por meio do contato multiétnico. PALAVRAS-CHAVE: Poloneses; Italianos; Contato Étnico; ColomboPR.

\begin{abstract}
This study aims to identify the presence of polish immigrants and their descendants in Colombo, Paraná. Historically, this city in the Metropolitan Region of Curitiba, is recognized by italian immigration, however, at the end of the 19th century, an expressive polish contingent also settled in their lands. Thus, the first objective of this research is to highlight the historical presence of this slavic ethnic group, and at the same time to identify the spaces, physical
\end{abstract}


and temporal, occupied by him in that city. It also aims to analyze the contacts that took place between polish and italians, under the view of the descendants of the latter in relation to the former. For this, narrative analysis was used as the methodology of Oral History. In this sense, an interview script was organized considering memory in the context of historical research. Therefore, the sources used are oral reports, all collected in 2019 by members of the Centro de Estudos Venetos in Paraná. In turn, the theoretical analysis is based on the discussions on ethnicity, presented by Poutignat and Streiff-Fenart, and on identity through differentiation, pointed out by Silva. Within the material collected, we highlight speeches that we can classify as promoters of ethnocultural boundaries built through multiethnic contact. KEYWORDS: Polish; Italians; Ethnic Contact; Colombo-PR.

RESUMO: Questo stùdio voe ricognosser a presensa dei imigranti poeachi e soi dissendenti in Coeombo, Paranà. Storicamente, questa sità dea Region Metrolitana de Curitiba ze cognossesta par via dea imigrassion taliana che ga rissevesto, ma ancora sol finae del sècoeo XIX, una granda sbranca poeaca anca ze rivà soe so tere. Cussita, el primo ogetivo de questa risserca ze parlar dea partissipassion stòrica de questo grupo slavo e, al stesso tempo, far vegner fora i posti, fîsichi e temporai, ocupà par iu soa deta comunità munissipae. Desìderasse anca, vedre come ze ndati i incontri tra poeachi e taliani, soto a vision dei dissendenti de questi ùltimi in relassion ai primi. Par questo, se ga doprà el stùdio dei raconti come modo de investigassion dea Stòrgia Orae. In questa diression, un mùcio de domande ze stà parecià ciapando a memòria come fontana par far vegner fora el saer stòrico. Lora, i documenti doprai i ze raconti orai, tuti tolti su sol ano de 2019 par membri del Sentro di Stùdii Véneti ntel Paranà. Par so volta, el stùdio teòrico se ga fato coa giuta dee discussion sora etnissità, presentà da Poutignat e da Streiff-Fenart, e anca sora identità par medo dea diferensiassion, come gien mostrà da Silva. Rento ee interviste studià, se ga catà modi de discorere che ga slevà frontiere ètnicoculturae che se ga fato par medo del incontro multiètnico. PAROECIAVE: Poeachi; Taliani; Incontro Ètnico; Colombo-PR.

\section{INTRODUÇÃO}

A presente pesquisa surgiu do anseio de investigar a história por meio da memória, e, mais ainda, da crença de que a forte relação que existe entre ambas é capaz de revelar processos de construção de identidades de grupos sociais, sobretudo, de agrupamentos étnicos formados por imigrantes e seus descendentes. Nesse sentido, acreditamos que a memória se mantém viva, ou seja, continua a existir pelo fato de que é sempre carregada 
por indivíduos e grupos vivos. Na nossa concepção, é esta dinâmica existencial que faz com que ela não seja estática, mas, ao contrário, esteja "em permanente evolução, aberta a dialética da lembrança e do esquecimento, inconsciente de suas deformações sucessivas, vulnerável a todos os usos e manipulações, susceptível de longas latências e de repentinas revitalizações" (NORA, 1993, p. 9).

Segundo o historiador Pierre Nora, que se dedicou ao estudo da identidade da nação francesa por meio da memória, isso se dá pela aceleração da história, que o autor define como um "arrancar do que ainda sobrou de vivido no calor da tradição, no mutismo do costume, na repetição do ancestral, sob o impulso de um sentimento histórico profundo" (1993, p. 7). Sendo assim, podemos afirmar que vários fatos e acontecimentos que ocorreram recentemente, tanto no âmbito nacional quanto também regional e local, e que visaram ressaltar a memória e a história da etnia polonesa em terras brasileiras, foram os responsáveis por despertar o desejo, tanto da realização desta pesquisa, como da sua divulgação por meio deste artigo.

Dentre eles, o primeiro acontecimento que podemos citar, que aguçou nossa curiosidade sobre o tema, ocorreu em meados de 2019. Tratou-se da instalação de um monumento intitulado Brasil-Polônia na cidade que constitui o recorte espacial de nossa investigação: o município de Colombo, no Paraná. O referido monumento, que é formado pelos mapas das duas nações e que contém no meio a imagem de um aperto de mãos, foi instalado na rotatória existente entre as ruas João Batista Stocco e Pedro Ossoski, próximo da divisa entre os bairros São Gabriel e Itajacuru. Essa ação nos trouxe de imediato as seguintes indagações: Por que este lugar foi o escolhido para abrigar o monumento? Qual a relação dessas localidades com os poloneses?

Um segundo fato, que muito provavelmente deve ter motivado o anterior, é que o ano de 2019 deu lugar às comemorações do aniversário de 150 anos de imigração polonesa no Brasil. Decorrente desse contexto, uma série de festejos e eventos foram realizados lembrando da chegada, em agosto de 1869, das primeiras 16 famílias de imigrantes poloneses, 78 pessoas, vindas da Alta Silésia para a região de Brusque, Santa Catarina (WACHOWICZ, 1973). Esse cenário nos trouxe outro questionamento: As famílias de descendentes de poloneses que vivem hoje em Colombo teriam alguma ligação ou relação direta com essa leva pioneira de imigrantes que desembarcou em terras brasileiras?

Ao iniciar a nossa investigação, em busca de respostas para as referidas questões, tomamos conhecimento de que pouco tempo antes, mais especificamente no final do ano de 2017, também ocorreu na cidade investigada a inauguração do Memorial Ítalo-Polonês, instalado junto ao Parque Municipal da Uva. O equipamento cultural, uma construção em 
madeira que pertenceu ao casal Alfredo Perin e Rosa Puka, ele descendente de italianos e ela de poloneses, passou a fazer parte das instalações do Museu Municipal.

Além de objetos doados pelos ex-proprietários do imóvel, o citado memorial recebeu ainda doações de outras pessoas, todas descendentes de famílias polonesas que há anos residem na cidade, por exemplo, Kachel, Purkot, Scrok, Soppa, Macioszek, com o nítido intuído de apontar para a forte presença deste outro grupo étnico na formação de Colombo. Isso porque este município da Região Metropolitana de Curitiba, que se emancipou da capital, em 1890, há muito tempo já é reconhecido como terra de imigração italiana, ao passo que pouco se mencionava até então sobre o expressivo contingente polonês que se instalou em algumas de suas localidades, desde o último quarto do século XIX. É exatamente esse processo histórico, que engloba tanto a instalação do referido grupo eslavo, quanto o contato étnico do mesmo com o outro grupo imigrante, que queremos analisar aqui. Portanto, é nossa intenção perceber como se deram as relações interétnicas entre os dois grupos imigrantes, poloneses e italianos.

E, por último, mas não menos importante, ainda no final do ano de 2019, foi realizado o I Encontro Internacional de Estudos Poloneses, nas dependências da Universidade Federal do Paraná, do qual tivemos a oportunidade de participar. O motivo da realização do evento, além da promoção e da divulgação do conhecimento científico promovido por pesquisas envolvendo a temática, foi a comemoração dos 10 anos do curso de Letras-Polonês da instituição. Foi o referido encontro que nos abriu espaço para apresentar o início de nossa pesquisa sobre o assunto, que acreditamos ser inédita, pois não encontramos nenhum escrito sobre ele. Ou seja, a imigração polonesa em Colombo ainda não foi estudada com afinco, pois foi sempre citada somente de maneira superficial por trabalhos que abrangem outras temáticas, sobretudo, a da imigração italiana.

Sendo assim, este estudo almeja preencher tal lacuna historiográfica, pois se propõe a evidenciar a presença dos imigrantes poloneses e seus descendentes na formação da cidade de Colombo, Paraná. Portanto, os principais objetivos do presente trabalho são ressaltar a trajetória do referido grupo étnico, identificando os espaços físicos e temporais ocupados por ele no município, e também, como já afirmamos, analisar os contatos que se deram entre poloneses e italianos, o que faremos a partir da visão dos descendentes destes últimos, que por muito tempo formaram o maior agrupamento étnico da cidade.

Para a realização desta empreitada fizemos uso da análise de narrativas como metodologia da História Oral, considerando a memória no âmbito da pesquisa histórica. Essa nossa crença na eficácia dessa perspectiva metodológica se dá, conforme nos orienta Portelli, pelo fato de que nela "o controle do discurso histórico permanece firme nas 
mãos do historiador", pois é ele "que seleciona as pessoas que serão entrevistadas, que contribui para a moldagem do testemunho colocando as questões e reagindo às respostas" (1997, p. 37).

Desta forma, as fontes utilizadas são narrativas e relatos orais em Talian (língua de herança mantida pelos descendentes de italianos no Brasil), coletados no município de Colombo, no ano de 2019, por pesquisadores do Centro de Estudos Vênetos no Paraná $(\mathrm{CEVEP})^{1}$. Esse grupo de pesquisa, do qual fazemos parte, já realizou 32 entrevistas com descendentes de italianos no município de Colombo. ${ }^{2}$ Especificamente para este trabalho, escolhemos para análise trechos de 4 narrativas, aquelas nas quais os entrevistados citaram os poloneses em seus relatos, sendo elas dos seguintes informantes: Cavassin (62 anos), Gasparin-Motin (96 anos), Mocelin (81 anos) e Mocelin-Pavin (93 anos). ${ }^{3}$

Sendo assim, dividimos o texto a seguir em duas partes. Primeiramente, por meio da consulta bibliográfica e de fontes escritas, vamos tratar da trajetória dos imigrantes poloneses até a sua instalação em terras colombenses, visando explicar de que forma isso aconteceu. A segunda se ocupará em analisar os contatos étnicos desse grupo com os colonos italianos que também se instalaram na região, tendo como fontes os relatos orais já mencionados e apoiando-se nas discussões sobre etnicidade apresentadas por Poutignat e Streiff-Fenart (1998) e sobre a identidade pela diferenciação elaborada por Tomaz Silva (2014), que dialogam com estudos de outros autores que apresentaremos em conjunto.

\section{A INSTALAÇÃO DE IMIGRANTES POLONESES EM COLOMBO}

Foi a partir da segunda metade do século XIX, que grandes levas de imigrantes

\footnotetext{
1 O CEVEP, cadastrado no CNPq desde maio de 2018, <http://dgp.cnpq.br/dgp/ espelhogrupo/345590>, é composto por integrantes das comunidades de Campo Largo/PR, Colombo/PR, Curitiba/PR e Lapa/PR, abarcando com seus pesquisadores áreas da linguística, arquitetura e patrimônio cultural, história, história da educação e design. Um dos principais objetivos do grupo é valorizar e resgatar o Talian falado na região por meio da realização de entrevistas com seus detentores.

${ }^{2} \mathrm{O}$ roteiro dessas entrevistas foi organizado com base na sociolinguística, porém sempre levando em consideração a relação da memória com a história, como afirmamos no início. É importante mencionar que todas as entrevistas possuem a ficha social dos informantes, assim como o TCLE (Termo de Consentimento Livre e Esclarecido) e a Autorização de Uso de Imagem, Som de Voz, Nome e Dados Biográficos assinados por eles.

${ }^{3}$ Os sobrenomes duplos têm a função de diferenciar o sexo dos entrevistados, pois referem-se exclusivamente as pessoas do sexo feminino, sendo que o primeiro é o sobrenome de solteira e o segundo aquele adquirido após o casamento.
} 
poloneses, assim como de outras etnias, começaram a se dirigir para o Brasil. Esta atração se deu porque nesse período o império brasileiro adotou uma forte política imigratória, visando a introdução de trabalhadores estrangeiros assalariados, a fim de substituir a mão de obra escrava, modelo que se estava esvaindo. Esse era o caso, sobretudo, da província de São Paulo, onde a maioria dos imigrantes foram colocados nas grandes lavouras de exportação, principalmente nas fazendas de produção de café.

Já na província do Paraná, por sua vez, os contingentes imigratórios foram destinados a criar uma agricultura de abastecimento de gêneros alimentícios de primeira necessidade, ocupando áreas não muito distantes dos centros urbanos (BALHANA; MACHADO; WESTPHALEN, 1969, p. 162). Somada a esta questão, da necessidade de braços para a produção agrícola, a introdução de imigrantes europeus, pacíficos e trabalhadores, almejava também, o branqueamento da raça brasileira e a ocupação dos vazios demográficos (NADALIN, 2001, p. 74).

A mesma época corresponde à conjuntura na qual a Polônia deixou de existir como um Estado Nação, pois teve suas terras dominadas pela Áustria, Rússia e Prússia, esta última pertencente ao Império Alemão. Essa situação de dominação fez com que o povo polonês, que vivia em uma sociedade onde o poder político e econômico não estava sob o seu controle, criasse "um sentimento de compensação em torno da mística do seu grupo étnico e cultural na defesa de sua polonidade ameaçada" (KIENIEWICZ apud IAROCHINSKI, 2000, p. 64).

Isso nos leva a crer que essa ameaça à cultura étnica, ao lado dos fatores políticos e econômicos, foi um forte motivo que impulsionou o deslocamento deste grupo. Assim, acreditamos que a decisão de emigrar e buscar novas terras no além-mar foi tomada também pensando em encontrar um lugar onde pudessem ter a liberdade para preservar sua língua, sua religião, seus costumes e suas tradições.

Foram das áreas ocupadas pelos prussianos que estavam sob administração alemã, conhecida como Prússia Ocidental, que compreendiam a Pomerânia e a Silésia, que partiram os primeiros contingentes migratórios que aportaram em terras brasileiras. Oficialmente, agosto de 1869 é reconhecido como o marco inicial da imigração polonesa no Brasil, devido à chegada do grupo formado por 78 pessoas, composto por 16 famílias (32 adultos) e sua prole (46 crianças).

Esses poloneses eram oriundos da aldeia de Siołkowice e outros vilarejos da redondeza, que ficavam a poucos quilômetros da cidade de Opole na Alta Silésia e, foram dirigidos para as Colônias Príncipe Dom Pedro e Itajahy, na região de Brusque, Santa Catarina. Os 16 chefes de família eram: Nicolau Wos, Francisco Pollak, Boaventura 
Pollak, Thomas Szymanowski, Simão Purkot, Felipe Kokot, Miguel Prudlo, Simão Otto, Domin Stempka, Casper Gbur, Balcer Gbur, Valentin Weber, Antonio Kania, Francisco Kania, Andreas Pampuch e Stefano Kachel (WACHOWICZ, 1973).

A este grupo pioneiro se uniram mais 16 casais (32 adultos) com seus filhos (54 crianças), somando 86 pessoas que desembarcaram em Santa Catarina em 1870, também oriundos da aldeia de Siołkowice e suas proximidades, na mesma região da Silésia, na época sob o domínio prussiano. Por sua vez, os chefes dessas outras famílias eram: Fabian Barcik, Gregório Hylla, Leonardo Fila, Leopoldo Jelen, André Kawicki, Martin Kampa, Blazyn Macioszek, Valentin Otto, Vicente Pampuch, Paulo Pollak, Martin Prudlik, José Purkot, José Scrok, Augusto Waldera, Ignácio Millek e Jacob Nalewala (WACHOWICZ, 1971, p. 113).

Essas duas levas foram trazidas para a região pelo engenheiro Sebastião Edmundo Woś Saporski, fato que rendeu a ele o título de pai da imigração polonesa no Brasil. Porém, o contingente polonês ficaria pouco tempo em Santa Catarina, porque poucos meses depois de receber os lotes de terra e construir suas casas, o grupo de imigrantes se deparou com o abandono por parte do governo brasileiro e se sentiu enganado por Saporski. Os colonos ficaram decepcionados e frustrados diante das inúmeras dificuldades e passaram a pedir que fossem encontradas novas terras para eles se fixarem.

Porém, devido à morosidade na realização desse desejo, podemos afirmar que foi ainda em território catarinense que esses poloneses se confrontaram pela primeira vez com outros grupos étnicos que já habitavam as terras brasileiras. Cremos que essas experiências não foram muito positivas, pois ou se perceberam rodeados pelos indígenas da região, como os índios botocudos, os quais por vezes precisaram enfrentar para poder cultivar a terra e poder colher o que haviam plantado, ou então, viram-se cercados por imigrantes alemães, os quais representavam os antigos inimigos que os haviam dominado, constrangido e feito abandonar suas aldeias de origem.

Acreditamos que essas duas experiências negativas de contatos étnicos também foram incentivadoras para que o agrupamento decidisse em definitivo pela transmigração para outra localidade e solicitasse insistentemente ao seu líder para que procurasse um novo espaço para conduzir o grupo. Assim, depois de conversas com as autoridades da Província do Paraná, Sebastião Saporski, tendo a ajuda do Padre Antonio Zielinski, recebeu a permissão e incentivo para deslocar o referido contingente para Curitiba. O governo provincial, inclusive, financiou parte das despesas do transporte e assentamento do grupo, fundando assim o primeiro núcleo colonial formado por maioria polonesa, junto à capital paranaense (IAROCHINSKI, 2000, p. 73). Trata-se da Colônia Pilarzinho, 
criada em meados do ano de 1871, distante apenas 5 quilômetros do centro da cidade, e ocupada pelos 164 poloneses que migraram de Santa Catarina.

Assim, estava inaugurada a vinda deste contingente étnico que a partir desse momento faria de Curitiba e região, assim como de todo o Paraná, terra de imigração polonesa. Isso porque uma verdadeira rede de imigração foi formada por parte destes eslavos, sendo que não demorou muito para que um terceiro grupo fosse atraído pelos pioneiros, que agora estavam satisfeitos com suas terras em ambiente curitibano. Tanto que por meio de correspondências fizeram chegar a notícia de boas novas e o convite aos seus parentes na Europa para que viessem se juntar a eles.

Dessa forma, em 1873, depois de entrarem pelo porto de São Francisco em Santa Catarina, chegaram mais 64 famílias, num total de 258 pessoas, também procedentes da Prússia Ocidental, oriundos das aldeias de Siołkowice, Lignów, Skurcz, Panczewo, Libenau, Nova Cyrkiew, Popielovo e Sturgost, que foram rapidamente trazidos para Curitiba. Nesta ocasião, os imigrantes foram destinados para um novo núcleo, que pelo que tudo indica, já estava sendo preparado para eles, e assim, formaram a Colônia Abranches, fundada em 10 de novembro daquele ano (WACHOWICZ, 1976, p. 13). ${ }^{4}$

No ano de 1875, ao tratar dessas duas colônias, Pilarzinho e Abranches, em seu relatório, o então Presidente da Província do Paraná, Adolfo Lamenha Lins, traznos a informação de que as famílias dos colonos nelas instalados enfrentavam um sério problema: "a pequenez do terreno que ocupam e que são absolutamente insuficientes para desenvolver-se qualquer cultura. Os lotes com 50 braças em quadro não permitem, entretanto, ser aumentados como aliás quisera o governo, porque a divisão feita o não permite" (1876, p. 88).

Defendemos que a falta de terra para o plantio foi a principal razão que fez com que muitos jovens imigrantes poloneses, ou então, a primeira geração de descendentes, viessem mais tarde a se estabelecer em terrenos no município vizinho de Colombo. Contudo, apesar desta dificuldade sobre os lotes serem pequenos, conforme apontou o então presidente da província da época, estas primeiras colônias prosperaram e os

\footnotetext{
${ }^{4}$ Os sobrenomes das famílias que compunham esse grupo eram: Piekarski, Dubiela, Krasinski, Schinka, Waldman, Czerwinski, Deller, Schwonka, Kurowski, Kajut, Ligman, Hejmowski, Schwarz, Kuchenny, Grabowski, Klass, Rafalski, Lass, Kozlowski, Dedeler, Zielonski, Flizikowski, Henning, Brzozowski, Dolata, Kaszubowski, Tarnowski, Haftka, Hela, Depka, Dodzinski, Glodzinski, Dibowski, Zielinski, Ziman, Kalinowski, Hella, Krajanski, Nowak, Pamplewski, Grochowski, Schlychta, Kowalski, Iwanski, Kracki, Langowski, Skrocki, Szczepanski, Piat, Koziedrowski, Derda, Dombrowski, Bunik, Sobienski e Popyja (WACHOWSKI, 1971, p. 116117).
} 
poloneses continuaram a fazer parte da política de colonização do Paraná.

Sendo assim, nesta fase inicial, que compreende as décadas de 1870 e 1880, mais levas desta etnia foram assentadas ao redor da capital, formando, junto com os imigrantes italianos, o chamado "cinturão verde" de abastecimento de gêneros alimentícios de Curitiba. Com este anseio em mente, no ano de 1875, foi a vez da fundação do núcleo colonial Santa Cândida, às margens do Rio Atuba e da Estrada da Graciosa. Esta colônia possuía inicialmente 49 lotes, onde foram instalados 168 poloneses e 40 suíços de língua francesa, aos quais foram agregadas mais terras em 1876, chegando a ser registrado o total de 64 lotes, devido à chegada de mais famílias polonesas. ${ }^{5}$

A maioria dos imigrantes assentados nesta nova colônia Santa Cândida eram oriundos das aldeias de Siołkowice, Narok, Popielow e Popielowa, ou seja, provinham das mesmas regiões da Silésia, então sob o jugo da Prússia, que seus vizinhos do Pilarzinho e Abranches (IAROCHINSKI, 2000, p. 86). Este fato reforça nossa ideia da formação de uma rede de imigração baseada em vínculos familiares e de antiga vizinhança que continuou a atrair os poloneses para o Paraná. De acordo com o jornal Gazeta Polska, de 22 de julho de 1893, que na ocasião publicou dados estatísticos sobre a população desta etnia em Curitiba, referentes ao ano 1884, somente essas 3 colônias já somavam um total de 860 imigrantes poloneses (IAROCHINSKI, 2000, p. 76).

Por fim, a última leva polonesa que contribuiu com a formação demográfica do município que estamos investigando, chegou em 1886, graças à instalação da Colônia Antonio Prado. Essa foi organizada também nas proximidades do rio Atuba, porém agora na divisa entre Colombo e Almirante Tamandaré. Por sua vez, este núcleo foi formado por 54 lotes, ocupados por 181 imigrantes, sendo que 112 eram de origem polonesa [26 famílias], e o restante eram italianos [12 famílias] (FERRARINI, 1992, p. 185). ${ }^{6}$

$\mathrm{O}$ sucesso destas colônias, nas quais os imigrantes poloneses dedicavam-se à

\footnotetext{
${ }^{5}$ De acordo com o livro de conta corrente $\mathrm{n}^{\circ} 837$ do DEAP-PR as famílias polonesas que se instalaram na Colônia Santa Cândida foram: Arasmus, Barick, Baudy, Czaja, Czebula, Dittmann, Dubiella, Gbur, Kachel, Kampa, Kania, Klink, Koch, Kolodrej, Kubis, Kulig, Kupka, Macioszek, Makiolka, Manka, Masienski, Matuszenski, Nadolny, Otto, Poykala, Prodeliky, Prodlo, Rolski, Rudetz, Schneider, Schultz, Skora, Skroch, Sluga, Soppa, Spisla, Sprada, Stolmach, Sveda, Voicik, Waldera, Walecko, Wenki e Wosch.

${ }^{6}$ Segundo o Livro de Cadastro do Núcleo Antonio Prado os colonos poloneses que ali se fixaram pertenciam as seguintes famílias: Balzieck, Daska, Felkner, Filla, Fillip, Jambiski, Kamarowiski, Kamoski, Kampa, Kawaleski, Kazubeck, Klimeck, Koslonski, Kubis, Kuroswiski, Kyla, Manika, Mickna, Mieleck, Neumann, Pampusch, Piekosch, Przypiny, Przypiski, Schlichting, Schwank, Wincart, Wistuba, Zocich.
} 
agricultura, causou de imediato dois resultados: a formação de famílias bem numerosas e a vinda de mais parentes da Polônia. O único problema seria então a falta de terras onde todos pudessem trabalhar e sustentar os novos núcleos familiares que se formavam. A solução encontrada foi ocupar novos lotes, localizados um pouco mais distantes, além do rio Atuba, portanto, que viriam a pertencer ao município vizinho de Colombo, mas que ao mesmo tempo eram terras contínuas das colônias de Santa Cândida e de Antônio Prado.

Assim, poucos anos depois, nas décadas de 1880 e 1890, em busca de mais terras para o plantio, muitos poloneses se instalaram em áreas que hoje correspondem aos bairros colombenses denominados de Colônia Antonio Prado, Itajacuru, Roça Grande e São Gabriel (antiga Ressaca). A fala de uma de nossas entrevistadas colaborou para esta nossa constatação: "E depois era assim, aqui pra cima, aqui no Prado, tinha só polacos. No Itajacuru tinha só polacos... E pra cá os italianos."7 (MOCELIN-PAVIN, 2019, tradução nossa).

O bairro Colônia Antonio Prado que é citado pela informante, corresponde à porção das terras que faziam parte do extinto núcleo colonial de mesmo nome. Esta foi a única parte do território de Colombo na qual os poloneses se instalaram desde o momento da chegada de suas famílias no Paraná, em 1886. Os demais núcleos desta etnia, localizados no Itajacuru, Roça Grande e São Gabriel, foram formados como uma extensão territorial da colônia Santa Cândida, instalada em 1875, às margens do Rio Atuba, divisa natural entre Colombo e Curitiba.

Por sua vez, as famílias destas localidades tinham uma forte ligação de parentesco, tanto com as famílias da referida colônia, como também com aquelas do Pilarzinho e Abranches. Esta última, inclusive, teve essa relação fortalecida pela ocupação de lotes contínuos que chegavam até o Santa Cândida, por meio da formação do núcleo polonês organizado no bairro Barreirinha. Dessa forma, destacamos, assim como reforçou a fala da nossa entrevistada apresentada anteriormente, que existiram áreas do município de Colombo que foram ocupadas exclusivamente por imigrantes poloneses, desde o final do século XIX, conforme apontamos no mapa a seguir:

\footnotetext{
${ }^{7}$ E dopo gera cussita: qua in cima, qua so'1 Prado, ghe gera soo poeachi. So'l Itajacuru ghe gera soo poeachi... E par quà i taliani. (Original em Talian).
} 


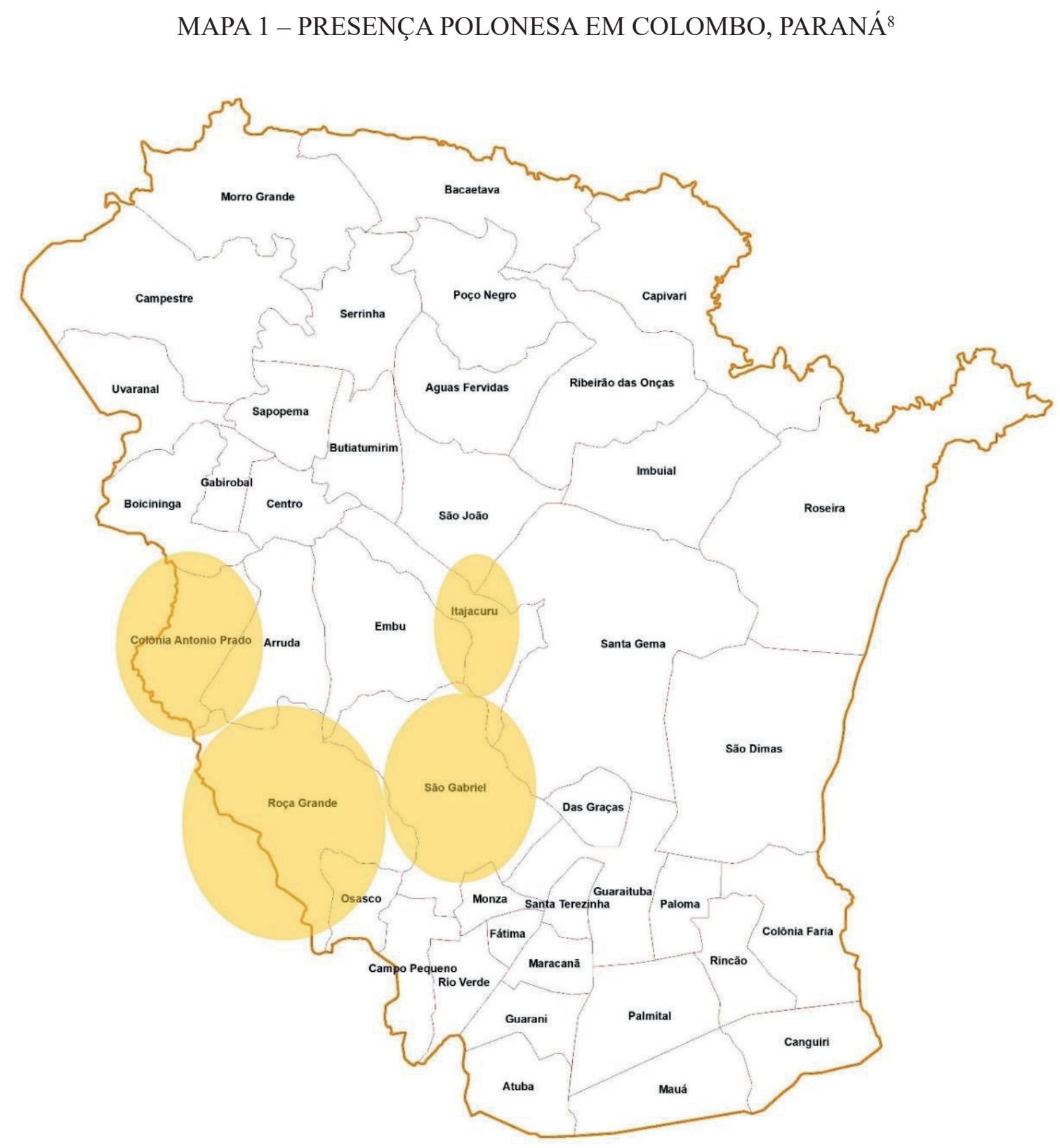

FONTE: O autor (2020).

No ano de 1937, o Consulado Geral da Polônia no Paraná realizou um censo em todo o Estado, com a intenção de saber quais cidades possuíam indivíduos poloneses em sua formação social. A pesquisa informou que no município de Colombo, onde havia

\footnotetext{
${ }^{8}$ Ilustração elaborada pelo autor tendo como base o mapa dos bairros do Município de Colombo, fornecido pela Secretaria de Desenvolvimento Urbano e Habitação da Prefeitura Municipal de Colombo.
} 
pouco mais de 4.000 habitantes, 760 eram de origem polonesa, o que correspondia a $19 \%$ da população (IAROCHINSKI, 2000, p. 75). Atualmente, foi possível elencar, por meio de consulta às bibliografias, de listas telefônicas e de nomes de rua, que as famílias polonesas continuam presentes na cidade, representadas pelos seguintes sobrenomes:

QUADRO 1 - SOBRENOMES POLONESES EM COLOMBO

\begin{tabular}{|c|c|c|c|c|}
\hline BALZIK & BARCIK & BAUDY & BIEDA & BOZEG \\
\hline BUDIK & BUGALSKI & BROCOWSKI & CIBULSKI & CZEBULA \\
\hline CZOCHER & DAMBINSKI & DASKA & DUGONSKI & DUSKI \\
\hline DUSZKA & FELKNER & FILA & FILIP & GAIDA \\
\hline GAIOWSKI & GBUR & GOLMI & GORSKI & GOZDECKI \\
\hline GOSZYC & GRABOSKI & HELA & HYLLA & JAMBINSKY \\
\hline JARDWESKI & KABICESKI & KACHEL & KAEL & KALINOWSKI \\
\hline KAMAROSKY & KAMINSKI & KAMOSKI & KAMPA & KANIA \\
\hline KAZUBECK & KLENK & KLIMEK & KOCHINSKI & KOKOT \\
\hline KOLOWSKI & KOSLONSKI & KOWALESKI & KRAINSKI & KRETSMER \\
\hline KUBIS & KULIG & KULIKOWSKI & KUPKA & KURICK \\
\hline KUROSWISKI & KUSMA & KYLA & LANGOWSKI & LEPINSKI \\
\hline MACIOSZEK & MASCIOSH & MAKIOLKA & MANIKA & MATRASKI \\
\hline MATUSZENK & MICKNA & MIKOS & MILEK & NADOLNY \\
\hline NEWMANN & NOWAK & NOWAKOSK & OSSOSKI & OTTO \\
\hline PAMPUCH & PAVLYK & PCHSPINA & PIEKARZ & PIEKAS \\
\hline PIOCH & PRODLOW & PRUDLINK & PRISZPIURA & PRZYBYLSKI \\
\hline PRZYPINSKI & PUKA & PORKOTE & RUDOWSKA & SCHLUGA \\
\hline SHWONKA & SIECZKO & SGODA & SKORA & SKROCH \\
\hline SLUGA & SPISLA & SPRADA & SPUCK & STARE \\
\hline STAROI & STOLMACH & STOLK & SZCZEPANSKI & SZLICHTA \\
\hline SZWEDA & TOMASZESKI & UNICZYCKI & URBAN & URBIK \\
\hline WALDYRA & WALESKO & WINCART & WISTUBA & WOCH \\
\hline WOICIK & WOS & WOTEKOSK & ZSOPPA & ZOCICH \\
\hline
\end{tabular}

FONTE: O autor.

Podemos notar que muitos sobrenomes, apesar de muitas vezes apresentarem variações em sua grafia, são os mesmos daqueles que compunham as três primeiras colônias criadas ao redor do centro urbano de Curitiba, Pilarzinho, Abranches e Santa Cândida, como também da Colônia Antonio Prado. Essa realidade nos revela que, os poloneses, que se instalaram em Colombo, são de fato aparentados dos grupos que primeiro se 
fixaram naqueles núcleos e que vieram a ocupar lotes de terra na municipalidade vizinha. Defendemos que se tratam daqueles que imigraram ainda jovens e aqui formaram seus núcleos familiares ao contrair matrimônio, ou então, dos que pertencem à primeira geração de descendentes nascidos no Brasil, ou ainda, de integrantes de novas levas que chegaram depois do momento da fundação das colônias, mas que possuem alguma forma de parentesco com as famílias pioneiras, que tiveram um papel de incentivadoras na decisão de emigrar dessas últimas, por meio da formação de uma rede de imigração.

\section{POLONESES X ITALIANOS: A ETNICIDADE PELA DIFERENCIAÇÃO}

Conforme apontamos anteriormente, estamos pautando nossa investigação em torno da discussão acerca da construção da etnicidade, no intuito de analisar as memórias de um grupo de descendentes de imigrantes italianos sobre outro agrupamento étnico: os poloneses instalados no município de Colombo, Paraná. Para isto, estamos considerando que a identidade étnica se produz por meio de um processo de diferenciação. Isso porque, acreditamos que as etnicidades são sempre identidades socioculturais construídas historicamente por meio de contatos interétnicos e não por meio do isolamento.

Esta é a ideia defendida por Poutignat e Streiff- Fenart, que foram fortemente influenciados pelo pensamento do antropólogo social Fredrik Barth. Esses estudiosos afirmam que "a etnicidade não se manifesta nas condições de isolamento, é ao contrário, a intensificação das interações características do mundo moderno e do universo urbano que torna saliente as identidades étnicas..." (1998, p. 124).

Essa afirmação nos leva a acreditar que a identidade étnica é construída por meio de um processo de atração e repulsa diante daqueles percebidos como iguais e diferentes dentro de uma sociedade. Seria, portanto, a comunicação interétnica que produziria marcas e fronteiras pelas quais os membros das sociedades se identificariam com um grupo social ao mesmo tempo que se diferenciariam de outros.

Sendo assim, podemos afirmar que um grupo étnico só existe a partir do outro, o que o primeiro é, depende na verdade do que o outro é. Em outras palavras, o que se é, depende do que não se é. Conforme nos exemplifica Silva:

\footnotetext{
A afirmação "sou brasileiro", na verdade, é parte de uma extensa cadeia de "negações", de expressões negativas de identidade, de diferenças. Por trás da afirmação "sou brasileiro" deve-se ler: "não sou argentino", "não sou chinês", "não sou japonês" e assim por diante, numa cadeia, neste caso, quase interminável. Admitamos: ficaria muito complicado pronunciar todas essas frases negativas cada vez que eu quisesse fazer
} 
uma declaração sobre minha identidade. A gramática nos permite a simplificação de simplesmente dizer "sou brasileiro". Como ocorre em outros casos, a gramática ajuda, mas também esconde. Da mesma forma, as afirmações sobre diferença só fazem sentido se compreendidas em sua relação com as afirmações sobre a identidade. (SILVA, 2014, p. 75)

Nessa direção, percebemos que a constituição de uma etnicidade se dá dentro de uma sociedade multiétnica por meio de declarações de quem pertence e não pertence à determinado grupo. Assim, o processo de identificação se produz pela inclusão e exclusão, pela demarcação de fronteiras étnicas que definem quem está dentro e quem está fora. É uma produção de identidade pela diferenciação, na qual há uma afirmação perene da existência de um "nós" e de um "eles", ou do "nós" perante os "outros".

Essa demarcação de fronteiras, essa separação e distinção, supõem e, ao mesmo tempo, afirmam e reafirmam relações. [...] Os pronomes "nós" e "eles" não são, aqui, simples categorias gramaticais, mas evidentes indicadores de posições-de-sujeito fortemente marcadas por relações de poder. (SILVA, 2014, p. 82)

Acreditamos, portanto, que as relações sociais entre grupos étnicos serão sempre pautadas e mantidas por relações de poder, e mais, é a própria existência dessas diferenças e desigualdades que permitiram criar e permitem manter a própria concepção de etnia. Segundo Cuche (1999), as identidades culturais surgem exatamente por conta das disputas e dos contrastes, das lutas e das relações sociais desiguais, e elas não existiriam se não houvesse esse choque, ou seja, se não ocorresse um processo de inclusão e exclusão. O referido sociólogo afirma que "é preciso então fazer uma análise polemológica das culturas, pois elas se revelam nos conflitos; elas se desenvolvem na tensão, às vezes na violência" (CUCHE, 1999, p. 144).

Na nossa concepção, diante desta luta empregada pelos grupos, a noção de poder na maioria das vezes, estará ligada a um discurso de superioridade e tradição. Para defender essa suposta superioridade, o grupo do "nós" fará a defesa dos indivíduos que a ele pertencem, afirmando que possuem melhores comportamentos sociais em relação aos “outros', àqueles que são identificados como membros de grupos que possuem tradições diferentes das suas. A diferença levará a comparação, que, por sua vez, produzirá afirmações discursivas por parte do primeiro acerca de sua superioridade, por exemplo, "nós" somos mais religiosos, mais trabalhadores, mais educados, do que "eles".

Segundo Elias e Scotson (2000), essa relação cria um modelo moral, onde os indivíduos considerados como os de dentro, os estabelecidos, são definidos como a "boa 
sociedade" e os de fora, os outsiders, seriam membros de um "grupo social inferior". Esses autores nos explicam que:

\begin{abstract}
... são chamados de establishment ao grupo que se autopercebe e que é reconhecido como uma "boa sociedade" mais poderosa e melhor, uma identidade social construída a partir de uma combinação singular de tradição, autoridade e influencia: establishment fundam seu poder no fato de serem modelo moral para os outros. Na língua inglesa o termo que completa a relação é outsiders, os não membros da "boa sociedade", pois estão fora dela. Trata-se de um conjunto heterogêneo e difuso de pessoas unidas por laços sociais menos intensos do que aqueles que unem os established (ELIAS; SCOTSON, 2000, p. 7)
\end{abstract}

Portanto, percebemos que esse discurso de superioridade e tradição se dará por meio de uma forte ligação entre os estabelecidos, ou seja, por laços sociais intensos que unem e caracterizam o grupo social. Cremos que essa forte coesão se deve aos signos de identidade, aos traços que definem os indivíduos como pertencentes a uma determinada sociedade. Da mesma forma, entendemos que a memória coletiva do grupo é capaz de embasar essas representações de pertencimento à medida que perpetuam esses sinais $\mathrm{e}$ discursos a respeito da identidade assumida. De acordo com o antropólogo Joël Candau, essa se constituirá em uma memória forte que influenciará no processo de constituição da identidade do sujeito.

Denomino memória forte, uma memória massiva, coerente, compacta e profunda, que se impõe a uma grande maioria dos membros de um grupo... Uma memória forte é uma memória organizadora no sentido de que é uma dimensão importante da estruturação de um grupo, e por exemplo da representação que ele vai ter de sua própria identidade. (CANDAU, 2012, p. 44)

Portanto, o último autor afirma que a memória forte é organizadora e estruturadora da identidade coletiva dos grupos étnicos. Dessa maneira, a memória também pode ser considerada como construtora e mantenedora desse sentimento de pertença e de diferenciação que é capaz de produzir uma representação de identidade, por isso mesmo é chamada de memória forte.

Pensamos que é esse tipo de memória que encontramos nos relatos dos descendentes de italianos entrevistados na cidade de Colombo. Uma memória forte, ancorada no fenômeno da imigração, que ultrapassa o acontecimento da viagem transoceânica realizada pelos antepassados, mas que ainda é capaz de promover processos 
de identificação étnica, mesmo quase um século e meio depois da chegada dos imigrantes em terras colombenses. Assim, os descendentes de italianos, por pertencerem ao grupo étnico majoritário, assumem uma postura de estabelecidos, ao mesmo tempo que tratam os demais agrupamentos étnicos, no caso aqui os poloneses, mas também os brasileiros que inclusive ali estavam antes deles, como sendo os outsiders.

Essa nossa ideia vai ao encontro com o que aponta o historiador Alistair Thomson, que pesquisou histórias de vida e experiências migratórias de senhores australianos. Após se debruçar sobre as memórias desses sujeitos por meio da história oral, o autor nos apresenta um conceito mais amplo sobre imigração:

Defino "migração" incluindo tanto migrações internacionais quanto intranacionais e, como a maioria dos estudos de história oral, enxergo a passagem física da migração de um lugar para o outro como apenas um evento em uma experiência migratória que abarca velhos e novos mundos e que continua por toda a vida do migrante e pelas gerações subsequentes. (THOMSON, 2002, p. 341-342)

Portanto, nos pautamos também nessa ideia ampliada a respeito do que é a imigração, já usada em outros estudos de história oral, que reconhece que o fenômeno vai além do deslocamento físico pontual e atinge também os descendentes dos sujeitos que migram. Nesta perspectiva, o fenômeno imigratório promoverá contatos interétnicos, que por sua vez irão produzir as marcas e fronteiras pelas quais os membros das sociedades se identificam como um grupo social ao mesmo tempo que se diferenciam de outros.

Esse processo de identificação e diferenciação faz uso dos hábitos e costumes, fazendo deles sinais particulares de grupos étnicos, como por exemplo a forma de vestir, como podemos perceber no seguinte trecho da fala de uma de nossas entrevistadas: "Me lembro bem de quando eu era moça, que as polacas iam na missa com aquelas saias bem largas e longas até os pés, com o lencinho na cabeça..." (MOCELIN-PAVIN, 2019, tradução nossa).

Notamos, que a ênfase é dada no que difere, ou seja, a vestimenta, e não no que iguala, que seria o fato de ambos os grupos serem católicos e frequentarem a missa. Outro aspecto, que foi evidenciado nas entrevistas, foi a diferença na língua falada pelos agrupamentos, como podemos conferir no diálogo a seguir:

\footnotetext{
${ }^{9}$ Me racordo ben de quando gera tosata, che 'e poeache 'e andava soa messa con quee cotoe ben larghe e 'onghe fin i pie, co'l fassoeto so'a testa... (Original em Talian).
} 
- Esta língua, você a falava só com a família, com os amigos?

- Só com a família, porque tinha muita vergonha, né. Vergonha porque se você fosse falar desta maneira lá que tinha... porque tinha... que nem eu te disse, tinha os polacos, que eram poucos né... então eles achavam uma coisa muito diferente.

- Mas eles não falavam na língua deles?

- Não, não, não, não, não... eles sabiam, mas eles achavam... e se... e se tirava sarro quando falava italiano e nos deixavam com vergonha. Eles não sabiam nem falar a sua, usavam só o português né. Mas quando nós falávamos alguma coisa em italiano... minha Nossa Senhora, como... como eles riam...

- Eles te remedavam?

- Remedavam. ${ }^{10}$ (CAVASSIN, 2019, tradução nossa)

O último relato revela que o descendente de italianos não falava a língua materna fora do ambiente familiar por ter vergonha, causada pela risada daqueles que não eram do seu grupo étnico e que, consequentemente, não entendiam o seu idioma. Por outro lado, o informante deixa claro que era um indivíduo bilíngue, ao usar a língua étnica em casa e o português em ambiente social, provavelmente o escolar. Tais informações nos apontam, que uma outra língua étnica, ou até mesmo a diferença de sotaque ao falar o português, era um sinal particular de diferenciação.

Já ao falar que haviam poloneses na região, notamos que o informante faz questão de afirmar que eles eram a minoria e que não sabiam falar nem a sua própria língua, só o português. Percebemos neste trecho, que era difundida uma ideia de que os poloneses não sabiam falar corretamente, que não mantinham sua língua étnica, deixando subtendido que possuíam menos conhecimento, ou seja, de que eram menos inteligentes que os italianos.

Portanto, notamos que os dois grupos agiam para fortalecer os lados de pertença ao seu grupo étnico, ao mesmo tempo que apontavam os outros como diferentes, na maioria das vezes rindo e inferiorizando os indivíduos dos outros agrupamentos étnicos com os quais mantinham alguma forma de contato.

Porém, em uma das narrativas conseguimos encontrar um pequeno trecho em que as línguas étnicas mantidas pelos dois agrupamentos de descendentes de imigrantes serviram

10 - Questa engoa, te palavi soeo co'a famegia, co i amighi? - Soeo co'a famegia, parche gera massa vergogna, ve'. Vergogna parchè te 'navi fora palar de questa magnera eà che i gera ... parche ghe gera... che gnan te go dito, ghe gera i poeachi, che gera puchi, ve'... e ora iuri i catava un mescero massa stragno. - Ma iuri non palava e soe engoe? - No, no, no, no, no... i saea, ma i catava i... se... i se... i... se ria de noantri co palava taliano e assava noantri con vergogna. Iuri i no saea gnanca palar a sua, che gera soeo el "português", ve'? Ma quando noantri palavino qualchecossa em taliano... Madona mia, quanto... i se ria... - I te cogionava? - Cogionava. (Original em Talian). 
para cruzar as barreiras impostas, e isso se deu por meio do desejo de aprendizado: "Uma vez eu tinha aprendido falar um pouco em polaco, mas me esqueci. Tinha uma moça, ela era polaca, eu a ensinava italiano e ela me ensinava polaco". ${ }^{11}$ (MOCELIN-PAVIN, 2019, tradução nossa).

Contudo, ao analisar as entrevistas com os descendentes de italianos, foi possível notar que os contatos étnicos foram na maioria das vezes pautados e mantidos por relações de poder que na maioria das vezes buscavam inferiorizar o outro grupo, como podemos ler na narrativa que apresentamos a seguir:

- Com os polacos podia se casar?

- Com os polacos? Não, não te davam em casamento aos polacos. Polacos são gente ruim. Eles eram gente ruim e vagabunda ${ }^{12}$ (GASPARIN-MOTIN, 2019, tradução nossa).

E em outra ainda:

Os polacos tinham o vício de beber, de ser bêbados, os polacos eram beberrões... Os italianos diziam que os polacos eram bêbados e os polacos diziam que os italianos eram briguentos, que diziam muitos palavrões. Por isso que eles não se combinavam..$^{13}$ (MOCELIN, 2019, tradução nossa).

Por meio destes últimos dois relatos, percebemos claramente que havia a tentativa em classificar pejorativamente o outro por parte de todos os grupos étnicos que estavam em contato. Por vezes, isso acontecia por meio da moral social e religiosa, e por outras, pelo trabalho. Nessa direção, um outro aspecto bastante notório nas entrevistas é o quanto os depoentes caracterizam os indivíduos pertencentes ao seu grupo étnico como dedicados ao trabalho, ao mesmo tempo, que silenciam o trabalho do outro, chegando ao ponto de classifica-lo como vagabundo, como foi possível exemplificar em um dos relatos anteriores.

\footnotetext{
${ }^{11}$ Una volta mi ghea imparà palar un poco in poeaco, ma me gò desmentegà. Ghea 'na tosata, ea gera poeaca, mi a ensegnava talian e ea me ensegnava poeaco. (Original em Talian).

${ }^{12}$ Con i poeachi se potea maridar? - Con i polachi? No, non te davino maridar ai polachi. Polachi i ze genti cativi. I gera genti cativi e vagabundi. (Original em Talian).

${ }^{13}$ Poeachi i ghea el vissio de bevre, de esser ciuchi, i poeachi i gera ciucatuni... I taliani disea che i poeachi i gera ciuchi e i poeachi i disea che i taliani i gera brontoiuni, che i disea massa paroe. Par queo che i no se combinava. (Original em Talian).
} 
Porém, houve exceções, pois alguns indivíduos quebravam essas barreiras étnicas a eles impostas, como por exemplo a regra de contrair matrimônio somente com pessoas da mesma origem étnica. De acordo com Ferrarini (1993), esse fenômeno pôde ser observado na família Manika. Primeiramente, esse núcleo familiar polonês chefiado por Robert Manika, fixou-se na Colônia Antonio Prado, que como vimos foi constituída por poloneses e italianos. Esse fato com certeza já proporcionou um contato maior e recíproco de usos e costumes. Posteriormente, os membros da referida família transferiram-se, fixando residência na Colônia Presidente Faria, que até então era composta unicamente de italianos. Sendo os únicos poloneses fixados naquele núcleo colonial, os filhos da família Manika contraíram matrimônio com os moradores locais, e acabaram por assimilar os costumes italianos do lugar, inclusive falando a língua Talian que até hoje é mantida naquela ex-colônia. (FERRARINI, 1993, p. 15).

\section{CONSIDERAÇÕES FINAIS}

Por meio de consulta à bibliografia e fontes escritas foi possível identificar que os imigrantes poloneses, instalados em terras colombenses, vieram com as levas oriundas da Prússia Ocidental, principalmente da Silésia, região de Opole, vindas da aldeia de Siołkowice e redondezas, territórios que na época estavam sob o domínio alemão. Ao chegarem no Paraná essas famílias se dirigiram primeiramente para as colônias do Pilarzinho (1870), Abranches (1873), Santa Cândida (1875), e posteriormente, Antonio Prado (1886).

A falta de terras nessas colônias, causada pela pequenez dos lotes, fez com que muitas famílias de poloneses se instalassem para além do Rio Atuba, na continuidade das colônias Santa Cândida e Antonio Prado, adentrando assim o território do município de Colombo. Acreditamos que isso se deu, sobretudo, no momento em que os jovens começaram a contrair matrimônio e a formar novos núcleos familiares, e consequentemente, precisaram de novos terrenos para garantir o sustento de sua prole, o que encontraram em terras colombenses. Assim, foram formados na cidade os bairros Itajacuru, Roça Grande e São Gabriel, que se tornaram verdadeiros núcleos de famílias polonesas ligadas aos pioneiros desta etnia, àqueles que se fixaram anteriormente nas colônias polonesas instaladas em Curitiba.

Dessa forma, pudemos compreender o porquê do monumento Brasil-Polônia, existente em Colombo, conforme citado na introdução deste artigo, ter sido colocado exatamente na divisa dos bairros do Itajacuru e São Gabriel. Com a ajuda do que definiu 
Certeau (2005), ao especificar as diferenças entre lugar e espaço, entendemos que houve a criação de um lugar de memória, a fim de enaltecer o espaço que os imigrantes poloneses transformaram e ocuparam efetivamente por meio de suas presenças e práticas sociais. Em outras palavras, foi criada uma dialética permanente na qual o espaço foi transformado em lugar e, o lugar referencia o espaço, já que o objeto fixo remete aos sujeitos históricos que ali agiram.

Já nas narrativas orais, obtidas por meio de entrevistas, percebemos que as relações de poder provocadas pelo contato étnico entre os agrupamentos de italianos e poloneses estiveram ligadas a discursos de superioridade produzidos pelo grupo do "nós". Para defender a suposta superioridade, o grupo do "nós" exaltava a figura dos indivíduos que a ele pertenciam, afirmando que possuíam melhores comportamentos sociais e morais (somos mais trabalhadores, mais comportados etc.) em relação aos "outros", que por sua vez eram inferiorizados por meio de algum estigma social (são bêbados, vagabundos, briguentos etc.).

Dessa maneira, houve a produção de discursos que geraram estigmas, que por sua vez funcionaram como barreiras entre italianos e poloneses, pois serviram para diferenciar uns dos outros. Portanto, dentro do material apurado, destacam-se os discursos promotores de fronteiras etnoculturais, construídos em meio ao contato multiétnico. Nessa direção, pensamos que um próximo passo para a pesquisa será ouvir os descendentes de poloneses, que como vimos, podem ser facilmente encontrados na região investigada. 


\section{FONTES ORAIS:}

CAVASSIN. Depoimento concedido em 30 de março de 2019.

GASPARIN-MOTIN. Depoimento concedido em 26 de julho de 2019.

MOCELIN-PAVIN. Depoimento concedido em 04 de maio de 2019.

MOCELIN. Depoimento concedido em 04 de maio de 2019.

\section{REFERÊNCIAS:}

BALHANA, Altiva P.; MACHADO, Brasil P.; WESTPHALEN, Cecília M. História do Paraná. v. 1. Curitiba: GRAFIPAR, 1969

CANDAU. Joël. Memória e identidade. São Paulo: Contexto, 2012.

CERTEAU, Michel de. A invenção do cotidiano: 1. artes de fazer. Petrópolis: Vozes, 2005.

CUCHE, Denys. A noção de cultura nas ciências sociais. Bauru: EDUSC, 1999.

ELIAS, Norbert; SCOTSON, John L. Os Estabelecidos e os outsiders. Rio de Janeiro: Jorge Zahar, 2000.

FERRARINI, Sebastião. O Município de Colombo. Curitiba: Champagnat, 1992.

FERRARINI, Sebastião. Alberto Manika, padioleiro da F.E.B. Curitiba: Champagnat, 1993.

IAROCHINSKI, Ulisses. Saga dos polacos. Curitiba: Gráfica Mansão, 2000.

LINS, Adolfo Lamenha. Relatório do Presidente da Província à Assembleia Legislativa do Paraná. Curitiba: Tip. da Viúva Lopes, 1876.

NADALIN, Sérgio Odilon. Paraná: ocupação do território, população e migrações. Curitiba: SEED, 2001.

NORA, Pierre. Entre memória e história: a problemática dos lugares. São Paulo, EDUC, 1993. 
PORTELLI, Alessandro. O que faz a história oral diferente. Projeto História, São Paulo, v. 14, fev., 1997, p. 25-39.

POUTIGNAT, Philippe; STREIFF-FENART, Jocelyne. Teorias de etnicidade: seguido de grupos étnicos e suas fronteiras de Fredrik Barth. São Paulo: UNESP, 1998.

SILVA, Tomaz Tadeu da. Identidade e diferença: a perspectiva dos Estudos Culturais. 15. ed. Petrópolis, RJ: Vozes, 2014.

THOMSON, Alistair. Histórias (co)movedoras: História Oral e estudos de migração. Revista Brasileira de História, São Paulo, v. 22, n. 44, 2002, p. 341-364.

WACHOWICZ, Ruy Christovam. Relação dos colonos polacos que da Colônia Brusque, Santa Catarina, imigraram ao Paraná e estabeleceram-se em 1871, no Rocio de Curitiba. Anais da Comunidade Brasileiro-Polonesa. Curitiba: Superintendência do Centenário da Imigração Polonesa ao Paraná, 1971. v. III.

WACHOWICZ, Ruy Christovam. Documentação dos Arquivos Brasileiros referente às Colônias Pilarzinho e Abranches. Anais da Comunidade Brasileiro-Polonesa. Curitiba: Superintendência do Centenário da Imigração Polonesa ao Paraná, 1973. v. VII.

WACHOWICZ, Ruy Christovam. Abranches: um estudo de História Demográfica. Curitiba: Editora Gráfica Vicentina, 1976. 